\title{
Design and Practice of Introduction to Basic Courses of Mathematical-Physics Science
}

\author{
Pang Jing, Hu Xiuzhen*, Zhang Weiguang, Zhang Yongzhi, Wu Liji, Zhang Ying, Wang Ruilin, Ha Sihua, Kan Hongmei \\ College of Science, Inner Mongolia University of Technology, Hohhot, China 010051 \\ *Corresponding author: Hu Xiuzhen, \\ E-mail: hh_xx_zz@163.com
}

\begin{abstract}
Advanced Mathematics, College Physics, and Engineering Mechanics are basic courses of Mathematicalphysics science that set up by college of science for all the college students. These courses are the basis for specialized course learning and are necessary for entrepreneurship and innovation. Lack of study motivation on basic courses from insufficient knowledge of these courses is the main cause of a high failure rate. Therefore, we're going to take introduction to basic courses of Mathematical-physics science as pointcut, and deeply integrate teaching contents of basic courses and specialized courses. Through setting up introduction to basic courses of Mathematical-physics science, we expect to direct students to realize the importance of basic course learning and then improve teaching quality of basic courses of Mathematical-physics science.
\end{abstract}

Keywords-Basic courses; College Mathematics; College Physics; Engineering Mechanics

\section{INTRODUCTION}

Advanced Mathematics, College Physics, Engineering Mechanics and many other basic courses are included in Mathematical-physics science basic course in our university. Mathematical-physics science basic course are important public basic courses for all departments of the university. They are key construction curriculum of the university and are also model lessons, quality courses, first-class courses of the Inner Mongolia, Autonomous Region. In order to improve teaching quality of basic courses, these courses are effectively reformed. The construction and development of these courses are paid much attention to.

Characteristics of these courses are long total curricular hours, broad teaching contents and large course capacity. With the change of number and quality of students, we learned from recently years' actual teaching that students have no clearly cognition of these basic courses. Their comprehension of knowledge system isn't deep, grasp of main knowledge points isn't solid, and ability of applying knowledge to subsequent courses is poor. In most students' mind, specialized courses are more useful, so that they prefer to pay much more attention on them. Correspondingly, they have less interest on basic courses and don't take them seriously. Thus, students' study effectiveness declines on basic courses. Considering above situations, we think that it's necessary to offer an Introduction to Mathematical-physics science basic course before setting up basic courses. Introduction to Mathematical-physics science basic course can help students grasp basic courses' contents

Inner Mongolia autonomous region education science planning project "Thirteenth Five years" (NGJGH201732); Inner Mongolia university of technology educational reform project $(2016237,2015105,2016241)$. and learn relativity among different curriculum better, especially the relationship between basic courses and specialized courses. Introduction to Mathematical-physics science basic course can also improve students' interest on basic courses and help students learn knowledge system structure comprehensively. Further, when students work on their specialty, basic courses equip students with basic knowledge and scientific literacy. On the other hand, doing research on optimizing contents of introduction to basic courses is a good opportunity to improve teaching quality of basic courses teaching team. In conclusion, research on a series of courses of introduction to basic course has a generalized value.

\section{DESIGN OF INTRODUCTION TO MATHEMATICAL- PHYSICS SCIENCE BASIC COURSE}

The main idea is that we deeply integrate basic courses and specialized courses by adjusting design of courses' contents. students should be aware of that basic courses learning is the basis of specialized courses learning. Only with a solid basis, they can do well on specialized courses. Our work concentrates on creating convenient study conditions for student and fostering students' consciousness of asking questions. Teaching methods are redesigned and teacher-student interaction is enhanced. With these reformations, we expect to stimulate students' study interest and guide students to use the right attitude to treat basic courses.

\section{A. Design of courses' contents}

Taking Advanced Mathematics, College Physics, and Engineering Mechanics as research objects, we do research on courses' knowledge system, teaching contents and overview of main knowledge points. For instance, College Physics mainly includes Force, Thermal, Light, Electric, and Atomic Physics. The knowledge system of College Physics looks the same as physics of middle school [1], but comparing with physics of middle school, research of knowledge points of College Physics is based on calculus and vector calculation of Advanced Mathematics [2]. Therefore, Advanced Mathematics is the basis of other basic courses. It's very important for students to learn Advanced Mathematics well.

When it comes to research of relationships among courses and relativity among knowledge, we find that knowledge among different courses are closely related and there should be an order on course arrangement. For instance, the study of 
Engineering Mechanics involves calculus calculation of Advanced Mathematics and force analysis of College Physics. Thus, Advanced Mathematics, College Physics and Engineering should be scheduled on two terms of the first year, and the first term of the second year, respectively.

How to introduce the relationship between these three courses and following specialized courses, and correlation between these three courses and the production practice should be discussed seriously. With the advance of the society and the development of technology and economy, the expansion of basic courses contents is essential for the introduction course. Scholars have already made great achievements on applying physical model, mathematical methods and force analysis to the research on engineering [3]. Showing some developed and acceptable application cases to students is beneficial to broaden students' horizon and make students' feel far-reaching effects of basic courses to both specialized courses and production practice. We intend to make students realize that basic knowledge learning is cornerstone of all researches, understand the importance of basic knowledge learning and finally make students be interested on these courses. For instance, learning of the knowledge of building and bridge design in Architecture must base on the learning of Engineering Mechanics. Besides, the research on gear design, mechanical erection and nanomaterial introduced in Mechanical Engineering and Material Engineering must base on the learning of College Physic and Engineering Mechanics [4-5].

\section{B. Design of the curriculum form}

Introduction to Mathematical-physics science basic course is opened for all freshmen as public selective. It is a 16 hours, 1 unit course and is given as lecture form by eight professors that come from different basic courses' research area. In another word, every professor lectures two hours and report a complete subject. Arranging different professor on different subjects can keep students' novelty on the introduction course.

Contents of introduction course is proposed by professors and decided by teaching group discussion. Introduction to Mathematical-physics science basic course contents' database is constructed, which includes all PPT and paper material used on the course. And we continually perfect Introduction to Mathematical-physics science basic course contents with guidance of teaching experience.

In order to guarantee study effect, and provide enough communication space, except for communication during class break, an App platform is built up. On one side, this platform is convenient for connection between faculties and students. On the other side, it gives a full play to modern teaching method and internet. All relevant contents of Introduction to Mathematical-physics science basic course can be shared on this platform, which is much easier for students to view and comment at any time. The software platform design builds up a solid foundation for setting up video class, Micro-Course Online Video and MOOC, which will be our next step.
The final assessment of Introduction to Mathematicalphysics science basic course is paper. A writing template will be given. At the end of class each professor should provide at least four paper topics to students and of course, paper topics should have a strong relationship with lecture contents. This way, students will have more than thirty topics to choose at the end of semester so that they can select a paper topic according to their own interest. The paper will be reviewed by corresponding professor.

\section{PRACTICE OF INTRODUCTION TO MATHEMATICAL- PHYSICS SCIENCE BASIC COURSE}

On spring semester, 2017 we opened Introduction to Mathematical-physics science basic course as selective for class of 2016 students. Four classes constituted by four small classes are selected as experimental classes. On spring semester, 2018 we opened Introduction to Mathematical-physics science basic course as selective for all class of 2017 students.

Through group discussion, Introduction to Mathematicalphysics science basic course contents were decided. PPT and paper topics for every professor's lecture were prepared. At present, paper and electronic material databases of Introduction to Mathematical-physics science basic course are preliminary built up. We will continually perfect it during following teaching practice.

In order to take advantage of mobile phone to facilitate students' learning, we used QQ as software platform. A big discussion group was built up for all of faculties and students in four experimental classes, more than five hundred people. PPT, paper topics and writing template would be put in the QQ group, so that students can view them at any time and have more chance to discuss these course contents with professors. At the same time, some contents that are related to lectures were discussed at regular times. At first, teachers raised instructive questions in the group, and then students always initiatively asked questions. This is a good situation that rarely happened on basic courses before. Through heated discussion in the group, both students and teacher learned more deeply about basic knowledge application. Through searching literature, students had a more deeply understand of basic knowledge. Common responses from students and teacher prove that through more frequent communication, students and faculties benefited from it a lot. For further promoting interactive teaching we also implemented a series of incentives. For instance, students who put forward meaningful questions or give correct answer to questions can get extra points.

We classified papers and sent to corresponding professors, and then combined students' grades on attendance, class performance and papers to give students' total grade on the course. The grade proportion is $17 \%$ excellent, $34 \%$ good, $40 \%$ average, $9 \%$ fair and $0 \%$ poor. An unexpected achievement of setting up introduction course is that a group of innovative students were fostered and selected into Labs to do research on innovative programs. 
During the course time, we designed questionnaire that has fourteen questions. Every question has at least four options. 516 questionnaires were given out, and 480 feedbacks were received. We did statistical analysis and drew proportion figures of answers on received questionnaires. The part results are as following.

1. Do you like Introduction to Mathematical-physics science basic course?
A. I like it very much
B. I like it
C. It's ok
D. I dislike it

2. How do you feel about the lecture teaching form of Introduction to Mathematical-physics science basic course?
A. excellent
B. good
C. not bad
D. bad

4. Do you figure out the relationship between basic courses and specialized courses through Introduction to Mathematicalphysics science basic course learning?
A. very clear
B. clear
C. basically clear
D. not clear at all

5. Do you think that Introduction to Mathematical-physics science basic course is helpful to following specialized courses learning?
A. very helpful
B. helpful
C. not be much helpful
D. not be helpful at all

6. Are your interest on Mathematical-physics science basic course improved by Introduction to Mathematical-physics science basic course?

A. I am more interested on it B. I pay more attention to learning of basic courses C. my interest am not be improved much D. I have no feeling about this.

8. How do you feel about that Introduction to Mathematical-physics science basic course can cultivate students innovative conscious?

A. I begin to have idea to participate in innovative activity B. I begin to be interested on innovative activity $\mathrm{C}$. I begin to learn about innovation D. It has no use for promoting innovation group?

10. How do you feel about the interaction by QQ chatting

A. It is much more convenient for uploading, downloading documents and communicating with others B. I don' t talk but it is convenient for communication C. I don' $t$ talk and I don' t download documents either. D. I don' t care about this and I am not in the group

11. How many documents do you download from QQ group?

A. I download them all. B. I download part of them. C. I download only one or two of them. D. I don' $t$ download anything. E. I am not in the group at all.

From the result of questionnaires, we find that the Introduction to Mathematical-physics science basic course is very popular and teaching methods are highly acceptable by students. Course contents can basically achieve the aim of the course set up and cultivate students' innovative conscious. Interactive App platform can promote communication.

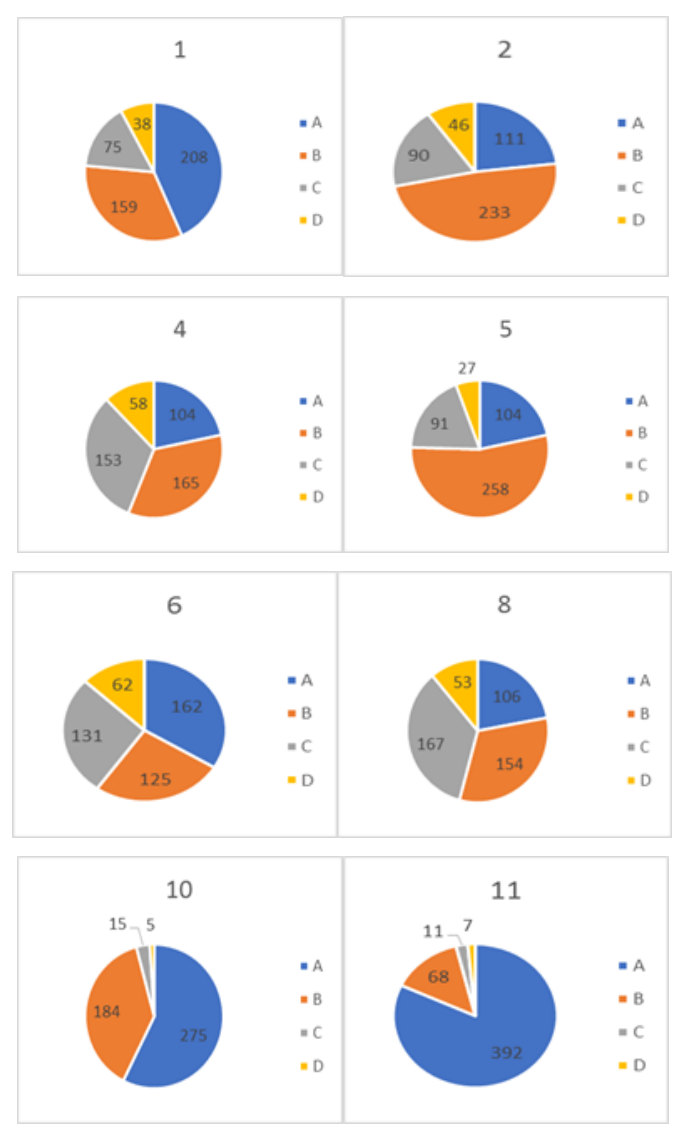

Fig. 1 The part statistical analysis results of questionnaires

Although, Introduction to Mathematical-physics science basic course as public selective achieved success, some insufficiencies appeared at the same time. The process of organizing teaching produces huge workload, such as, organizing course contents discussion, course arrangement, building up and maintaining the chatting group, classification of papers, gathering grades, questionnaires and so on. Because lectures are given by different professors and course capacity is huge, students have more opportunities to skip class. Therefore, it's important to further discuss organization and management of students. In addition, although paper template is given, the quality of papers is still unsatisfactory. It is labored for students to write papers since freshmen haven't accepted any writing training. Except for having difficulty on searching literature and using wrong citation format, students' expressions are not fluent and the logistic of paper is bad. What even worse is that students have no innovative ideas, the situation that students copy existing research results online is not rare. 


\section{CONCLUSION}

The setting up of Introduction to Mathematical-physics science basic course is totally an attempt that has no previous experience can be used for reference. We use a mixed teaching design on no matter teaching contents or teaching methods. Our purpose of course design is to try best to make students be interested on the course. Thus, we priority use advanced and new methods as far as possible. From questionnaires, we can see that students do benefit from introduction course. And a better teaching effect is achieved. For instance, students' interest is cultivated and a group of innovative students are discovered. At the same time, the teacher group further develops correlation among basic courses, specialized courses and social production practice. Therefore, setting up introduction course has a positive effect on promoting teaching quality of faculties as well.

\section{ACKNOWLEDGMENT}

This work was supported by Inner Mongolia autonomous region education science planning project "Thirteenth Five years" (NGJGH201732); Inner Mongolia university of technology educational reform project (2016237, 2015105, 2016241).

\section{REFERENCES}

[1] F. Yanxiao, W. Xiaogang and Ch. Junlang, "The research of university physics and middle school physics effectively of new college entrance examination mode", Course Education Research, vol. 1, pp. 158, January 2018. (In Chinese)

[2] Zh. Peihua, "Training the need for university mathematics calculus courses", Science research to solve problems, vol. 12, pp. 18, December, 2016. (In Chinese)

[3] S. Guanglin, H. Jiangchun, Zh. Yuhui and Y. Mu, "Mining engineering examples in the application of engineering mechanics teaching research", Henan building materials, vol. 1, pp. 35-36, January 2018. (In Chinese)

[4] L. Yan, "Training of university physics teaching reform of guided by professional personnel", Heilongjiang education (higher education research and evaluation), vol. 3, pp. 53-54, September 2018. (In Chinese)

[5] L. Guozhen, Q. Jie and Z. Taocheng," Analysis and interpretation of the first law thermodynamics“, Course Education Research, vol. 9, pp. 135-136, September 2017. (In Chinese) 